\title{
Cholecystokinin octapeptide stimulates phasic and tonic pyloric motility in healthy humans
}

\author{
R Fraser, D Fone, $M$ Horowitz, J Dent
}

\begin{abstract}
Stimulation of localised pyloric contractions may be an important mechanism in the slowing of gastric emptying by cholecystokinin infusion. The effect of cholecystokinin octapeptide on fasting pyloric motility was investigated in 14 healthy volunteers. Antral, pyloric, and duodenal pressure responses to normal saline and graded injections of cholecystokinin octapeptide $(5,10$, and $20 \mathrm{ng} / \mathrm{kg}$ ) were measured. Injections were given double blind and in randomised order. All doses of cholecystokinin octapeptide initially stimulated ( $p<0.05$ cf saline) phasic pressure waves localised to the pylorus - the median number of pyloric pressure waves in the 5 minutes after injection being $0,3 \cdot 5,6$, and 7 for the saline and the $5,10,20 \mathrm{ng} / \mathrm{kg}$ cholecystokinin octapeptide injections respectively. The phasic pyloric motor response to $20 \mathrm{ng} / \mathrm{kg}$ cholecystokinin octapeptide injection was greater than that to $5 \mathrm{ng} / \mathrm{kg}(\mathrm{p}<0.05)$. Basal pyloric pressure increased after $20 \mathrm{ng} / \mathrm{kg}(1.0 \mathrm{v}$ $0.2 \mathrm{~mm} \mathrm{Hg}, \mathrm{p}<0.05$ cf saline). Antral and duodenal pressure waves were suppressed initially by all doses of cholecystokinin ( $p<0.05$ cf saline). Subsequently, 20 of the 42 cholecystokinin octapeptide, injections but none of the saline injections, were followed by antropyloric pressure waves. Atropine, $15 \mu \mathrm{g} / \mathrm{kg}$ iv as a bolus, and then $4 \mu \mathrm{g} / \mathrm{kg} / \mathrm{hour}$ iv as an infusion, had no effect on the stimulation of localised phasic pyloric pressure waves by cholecystokinin octapeptide $10 \mathrm{ng} / \mathrm{kg}$. It is concluded that stimulation of pyloric contractions and suppression of antral and proximal duodenal motility may contribute to the slowing of gastric emptying produced by cholecystokinin.
\end{abstract}

(Gut 1993; 34: 33-37)

The orderly emptying of digesta from the stomach into the small intestine involves a complex interaction of neural and hormonal mechanisms acting on different parts of the stomach and duodenum. There is now considerable evidence that cholecystokinin (CCK), which is released in response to ingestion of nutrient meals containing fat or protein, modifies gastric emptying. Intravenous infusions of exogenous cholecystokinin octapeptide (CCK-8) and CCK-33 have been shown to slow gastric emptying. ${ }^{12}$ Furthermore, the CCK antagonist loxiglumide, significantly accelerated gastric emptying of a liquid test meal, ${ }^{3}$ although this result was not confirmed with a different antagonist. ${ }^{4}$ Recent studies have shown that the pylorus may be an important motor mechanism in the regulation of stomach emptying. ${ }^{56}$
Despite the evidence that $\mathrm{CCK}$ is important in regulating gastric emptying, there is limited information about its effect on the motility of the distal stomach in humans. In particular, there are virtually no data about the human pyloric response to CCK, although animal studies indicate that CCK stimulates localised pyloric contractions. ${ }^{7-9}$

An earlier study in humans reported increased pyloric tone during CCK-8 infusion, ${ }^{10}$ but no evidence of localised phasic pyloric contractions. The latter pattern of pyloric motility is seen with several stimulants of pyloric contractions in humans $^{1112}$ and with CCK in animals. ${ }^{9}$ The previous measurements of pyloric pressure responses to CCK-8 in humans were performed with the pull-through method which provides only infrequent samples, a significant limitation, as pyloric pressure shows considerable variability with time. The aim of the current study was to use a technique that allows continuous monitoring of pyloric pressure in order to examine more definitively the effects of $\mathrm{CCK}-8$ on fasting pyloric, antral, and duodenal motor activity in healthy humans. A secondary aim was to determine the role of muscarinic pathways in mediation of this response.

\section{Methods}

\section{SUBJECTS}

Antropyloroduodenal pressures were recorded in 14 healthy volunteers (seven men, seven women), aged between 18 and 32 years. No subject had a previous history of gastrointestinal disease or was taking any medication. Smoking was prohibited on the morning of the study. The protocol was approved by the Human Ethics Committee of the Royal Adelaide Hospital.

\section{MANOMETRIC ASSEMBLY}

The manometric catheter was similar to that used in other recent studies. ${ }^{11-13}$ It incorporated a $5 \mathrm{~cm}$ long sleeve sensor positioned across the pylorus to monitor pyloric pressures. Three side holes were located at $1 \mathrm{~cm}$ intervals along the sleeve to allow effective discrimination between contractions localised to the pylorus and short segment antropyloric contractions. Side holes were also located in the distal antrum 2 and $4 \mathrm{~cm}$ proximal to the sleeve, and in the proximal duodenum 3 and $6 \mathrm{~cm}$ distal to the sleeve. Simultaneously with pressure recording, side holes at each end of the sleeve monitored transmucosal potential difference (TMPD) via flowing saline electrodes. Data were recorded on a 12 channel recorder (model 7D; Grass Instrument Co, Quincy, MA, USA). 
Figure 1: Manometric recording from antrum pylorus (sleeve), and duodenum for 2 minutes before and 3 minutes after intravenous administration of $(A)$ saline and $(B)$ cholecystokinin octapeptide $(C C K-8)(20 \mathrm{ng} / \mathrm{kg})$. After the $C C K-8$ infusion there is stimulation of isolated pyloric pressure waves and suppression of antral and duodenal motility. The saline infusion has no effect on the motor patterns.
EXPERIMENTAL PROTOCOL

Studies began at $10 \mathrm{am}$ after an overnight fast. An intravenous catheter was placed in the left cubital fossa, and a manometric catheter was passed transnasally. The sleeve position was monitored continuously with dual point measurement of transmucosal potential difference (TMPD); the catheter was advanced or withdrawn to maintain the sleeve across the gastroduodenal TMPD gradient. ${ }^{11-13}$ After correct positioning of the catheter, each subject was given four different injections, each over 30 seconds, in randomised order and under double-blind conditions. The effects of intravenous injections of cholecystokinin octapeptide ( $5 \mathrm{ng} / \mathrm{kg}, 10 \mathrm{ng} / \mathrm{kg}$, and $20 \mathrm{ng} / \mathrm{kg}$ ), and a control bolus of normal saline were measured in each subject. The first injection was administered 10 minutes after completion of a duodenal phase 3 activity front; the subsequent three injections were given after consecutive 15 minute intervals during phase 1 or 2 of the interdigestive motor cycle. Fifteen minutes after the fourth injection, each subject received an intravenous bolus of atropine $(15 \mu \mathrm{g} / \mathrm{kg}$ over 30 seconds), followed by an atropine infusion ( $4 \mu \mathrm{g} / \mathrm{kg} /$ hour iv). Fifteen minutes after the atropine bolus, a second bolus of CCK-8 (10 $\mathrm{ng} / \mathrm{kg}$ ) was given.

In each subject heart rate was determined by palpation of the radial pulse immediately before and 15 minutes after the atropine bolus. At the same time, each volunteer was asked to report the degree of mouth dryness experienced, using a visual analogue scale from 0 to 10 , where 0 indicated 'normal, not dry' and 10 as 'dry as possible'. Volunteers were also examined for pupillary dilatation and asked about blurred vision.

\section{ANALYSIS OF MANOMETRIC TRACING}

Tracings were only analysed if the sleeve sensor was correctly positioned across the pylorus, according to previously published criteria -

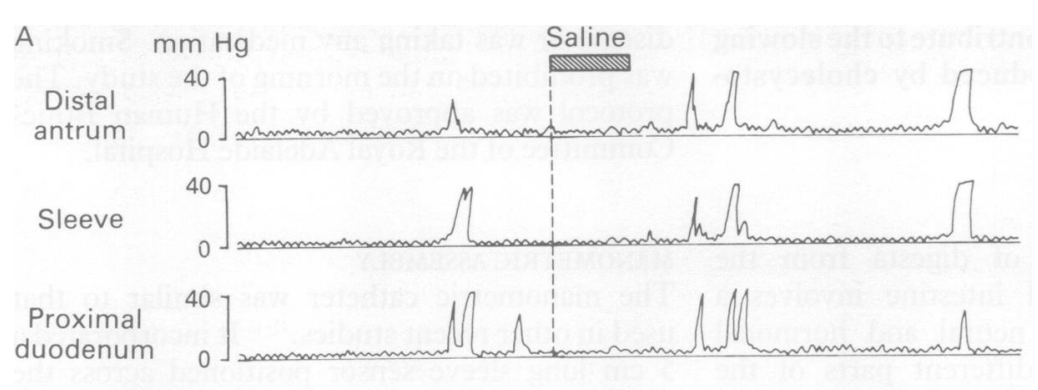

$30 \mathrm{~s}$

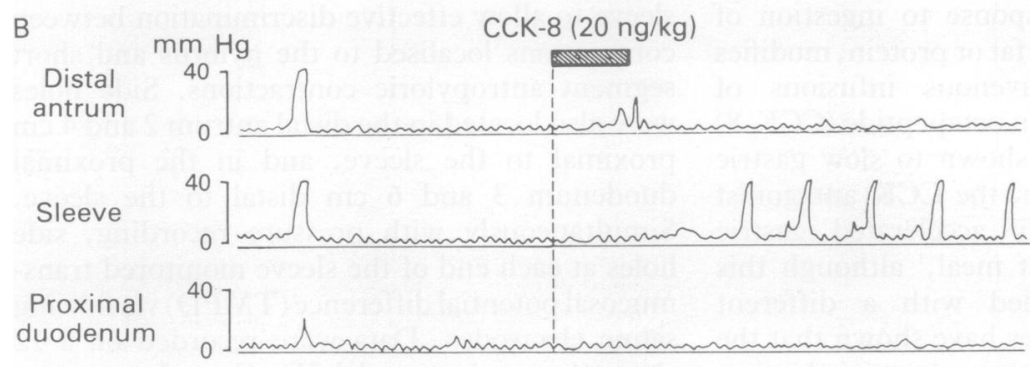

viz that the antral TMPD was more negative than $-20 \mathrm{mV}$, the duodenal TMPD was more positive than $-15 \mathrm{mV}$ and the difference between the antral and duodenal TMPD measurements was at least $15 \mathrm{mV} \cdot{ }^{11-13}$ The assembly was positioned correctly according to TMPD criteria for 1050 minutes out of a possible 1120 minutes of recording time.

Pressure waves were scored if their amplitude was greater than or equal to $10 \mathrm{~mm} \mathrm{Hg}$. Waves recorded by the sleeve sensor were classified as localised or isolated pyloric pressure waves (IPPWs) when they occurred in the absence of a wave of any amplitude in the antral or duodenal TMPD side holes and were recorded by no more than one side hole along the sleeve. ${ }^{11-13}$ The phasic pyloric responses to each injection were measured by counting the IPPWs for the 5 minute periods immediately before and after its administration.

Basal pyloric pressure was measured for each minute of the study by determining the end expiratory pressure recorded by the sleeve after phasic events had been edited. The pressure in the most distal antral side hole was used as a reference. ${ }^{11-13}$ A 5 minute average for basal pyloric pressure was calculated before and after each intravenous infusion. ${ }^{11-13}$

Antral and duodenal motor activities were assessed by counting the number of pressure waves recorded for the 5 minute intervals before and after each infusion by the antral TMPD and the most distal duodenal side hole.

\section{STATISTICAL ANALYSIS}

Values were compared for the 5 minute periods immediately before and after the bolus injections. The Wilcoxon matched pairs signed ranks test was used to compare the data. A p value of $<0.05$ was considered significant in all analyses. All manometric measurements were expressed as median values and interquartile ranges.

\section{Results}

Mild nausea was reported by eight subjects during the experiment. This occurred during injection of either $5 \mathrm{ng} / \mathrm{kg}$ (two subjects), $10 \mathrm{ng} / \mathrm{kg}$ (three subjects), or $20 \mathrm{ng} / \mathrm{kg}$ (three subjects) doses of CCK-8. In all cases nausea lasted less than 60 seconds and had no discernible effect on antral or pyloric pressure waves. No other untoward effects were reported during or immediately after either the CCK- 8 or saline injections. After atropine, all subjects showed evidence of muscarinic blockade with a significant increase in heart rate (median 72 beats/min (range 54-78) before atropine, 102 (range 72-138) after atropine $(\mathrm{p}<0 \cdot 01)$. All subjects also reported an increase in mouth dryness, with an increase in the median visual analogue score from 4 to $9(p<0.01)$.

\section{IPPW}

Examples of manometric recordings made during saline and CCK-8 injections are shown in Figure 1 (A) and (B). CCK-8 stimulated isolated pyloric pressure waves at all doses when compared with 


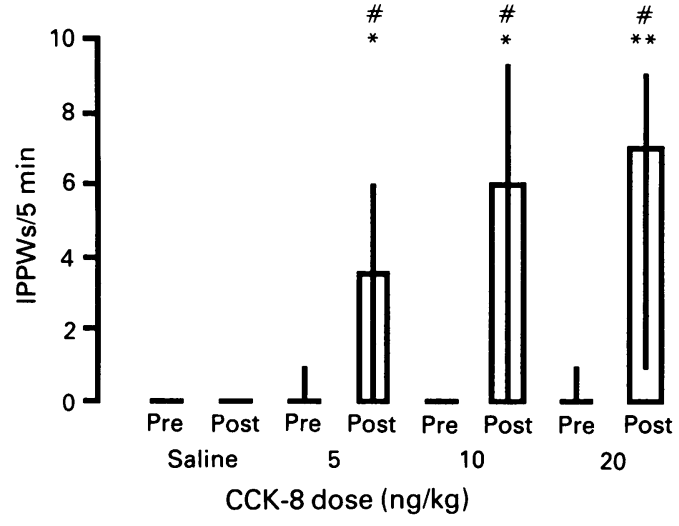

Figure 2: Effects of cholecystokinin octapeptide $(C C K-8)$ and saline on isolated pyloric pressure waves (median values and interquartile ranges for 5 minutes before and after each injection). There is significant dose-dependent stimulation with $C C K\left({ }^{\star} p<0.05\right.$ compared with values before injection, $\star \star p<0.01$ compared with values before injection, $\# p<0.01$ compared with saline).

both pre-injection values for CCK-8 and postinjection values for saline (Fig 2). The IPPW response to $20 \mathrm{ng} / \mathrm{kg} \mathrm{CCK}-8$ was significantly greater than to $5 \mathrm{ng} / \mathrm{kg}(\mathrm{p}<0.05)$, but not to $10 \mathrm{ng} / \mathrm{kg}$. Isolated pyloric pressure waves occurred in only four volunteers during any of the control periods and were seen in only one subject after saline injection. The latency of the IPPW response (the time from the start of the injection to the onset of the first IPPW) was dose dependent, being 220 seconds for $5 \mathrm{ng} / \mathrm{kg}, 80$ seconds for $10 \mathrm{ng} / \mathrm{kg}$, and 70 seconds for $20 \mathrm{ng} / \mathrm{kg}$. This latency was significantly shorter for $20 \mathrm{ng} / \mathrm{kg}$ than for $5 \mathrm{ng} / \mathrm{kg}(\mathrm{p}<0.05)$.

\section{BASIC PYLORIC PRESSURE}

There was no significant change in the basal pyloric pressure over the 5 minutes after injection for the group as a whole with saline injection or CCK-8 $5 \mathrm{ng} / \mathrm{kg}$ and $10 \mathrm{ng} / \mathrm{kg}$. Increases in basal pressure lasting 30 seconds to 3 minutes were, however, recorded after $5 \mathrm{ng} / \mathrm{kg}$ in four subjects and after $10 \mathrm{ng} / \mathrm{kg}$ in seven subjects. The CCK-8 $20 \mathrm{ng} / \mathrm{kg}$ dose resulted in a significant increase in basal pyloric pressure $(\mathrm{p}<0.05)$ in the 5 minutes after injection (Fig 3).

ANTRAL AND DUODENAL PRESSURE WAVES

CCK-8 also caused a consistent initial sup-


Figure 3: Basal pyloric pressure responses for the 5 minutes before and after injections of saline and cholecystokinin octapeptide $(C C K-8)(20 \mathrm{ng} / \mathrm{kg})$. There was a significant increase after $C C K-8$ administration ( $p<0.05$ compared with values before injection). pression of antral and duodenal pressure waves (Fig 1). Figures 4 and 5 show the suppressive effect of all doses of CCK-8 on antral and duodenal pressure waves in the first 5 minutes after injection when compared with the 5 minutes before CCK-8 and after saline injection $(\mathrm{p}<0.01)$.

In the 5 to 10 minutes after CCK-8, there was stimulation of a second pattern of motility in 20 of the 42 CCK- 8 injections. This consisted of antropyloric contractions which extended over 2 to $5 \mathrm{~cm}$ proximal to the pylorus. This stimulation lasted for 2 to 4 minutes and was not significantly related to the dose of CCK-8. This pattern of contractions was not seen after the saline injections $(\mathrm{p}<0.01)$, although phase 2 activity continued after some of these injections. No antropyloric contractions were seen after atropine, either before or after CCK-8 $10 \mathrm{ng} / \mathrm{kg}$.

Atropine administration had no impact on the pyloric motor responses to CCK. Before the administration of CCK-8, IPPWs were seen in only one subject and antral or duodenal pressure waves were recorded in only two subjects. The phasic pyloric response to CCK-8 persisted after atropine. The CCK-8 response after atropine administration (Fig 6) was no different from the response before atropine $(p>0 \cdot 6)$. CCK-8 resulted in an increase in basal pressure in only four subjects after atropine; data were insufficient for useful statistical analysis.

\section{Discussion}

These results show that CCK-8 stimulates isolated pyloric pressure waves (IPPWs) and pyloric tone in fasted healthy humans. The pyloric stimulation was dose-dependent and associated with suppression of both antral and proximal duodenal contractions. This combination of pyloric stimulation and antroduodenal motor suppression is identical to that previously reported in response to intraduodenal lipid and dextrose infusion. ${ }^{1213}$ Although the doses of CCK-8 used are likely to be nonphysiological, they show, for the first time in healthy humans, that CCK- 8 produces a pattern of antropyloroduodenal motility seen during small intestinal nutrient stimulation. The mild

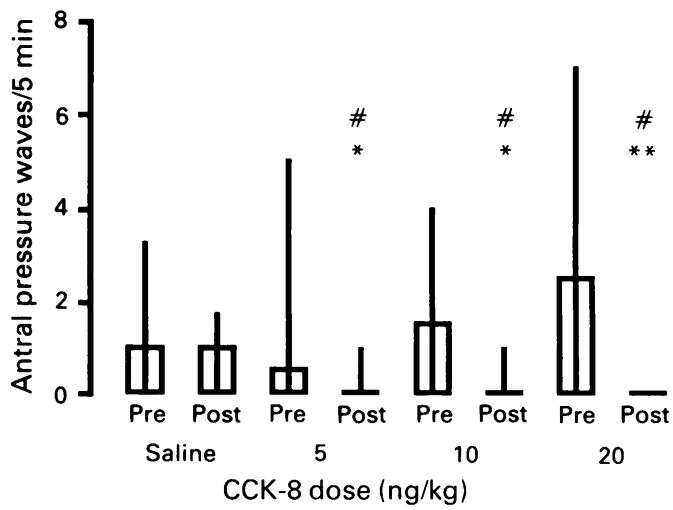

Figure 4: Effects of cholecystokinin octapeptide $(C C K-8)$ and saline on distal antral pressure waves (median values and interquartile ranges for 5 minutes before and after each injection). There is suppression of antral pressure waves after all doses of $C C K-8\left({ }^{\star} p<0.05\right.$ and ${ }^{\star} \star p<0.01$ compared with values before injection, $\# p<0.05$ compared with saline). 
Figure 5: Effects of cholecystokinin octapeptide $(C C K-8)$ and saline on duodenal pressure waves (median values and interquartile ranges for 5 minutes before and after each injection). There is suppression of antral pressure waves after all doses of $C C K-8\left({ }^{\star} p<0.05\right.$ and $\star \star p<0.01$ compared with values before injection, $\# p<0.05$ compared with saline).



nausea experienced by some subjects seems unlikely to have influenced the results.

Previous studies in humans have suggested that CCK-8 stimulates pyloric tone, but these have suffered from major technical limitations. In an endoscopic study on patients, Munk et al reported an acute reduction in pyloric diameter and an increase in pyloric pressure after CCK-8 injection, using a combination of direct observation of the pylorus and pull through manometry..$^{14}$ In studies in healthy human volunteers, also with a pull through technique, Phaosawasdi and Fisher reported that CCK-8 increased basal pyloric pressure. ${ }^{10}$ At variance with our findings, these authors did not record stimulation of IPPWs by CCK-8. The difference between our results and those of Phaosawasdi and Fisher ${ }^{10}$ may be caused by differences in manometric technique or in the dosage regimens used for CCK-8 administration. The pull through technique, as used in the earlier study, provides only brief sampling of data on pyloric pressures which may have resulted in the failure to detect the IPPW response. In the current study, the use of a sleeve sensor together with continuous monitoring of TMPD, allowed us to monitor pressures effectively from the narrow pylorus. Furthermore, Phaosawasdi and Fisher ${ }^{10}$ began their infusion 30 minutes before beginning pyloric motility measurement, and any phasic response may have attenuated by the time measurements were undertaken.

Studies in several animal species contribute to knowledge about the effects of CCK on pyloric motor function. Despite the use of apparently adequate techniques, there is a lack of agreement

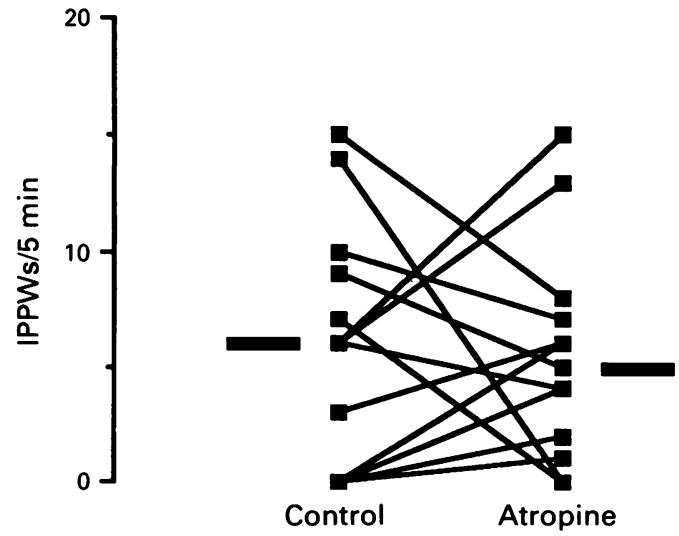

about the effect of CCK on the pylorus in the cat. An initial report showed that CCK-8 led to relaxation of the feline pylorus in 20 of 29 animals and either tonic or phasic contraction of this region in the remainder. ${ }^{15}$ Subsequently, Reynolds et al reported stimulation of pyloric contractions after CCK-8 administration which were not blocked by naloxone. ${ }^{16}$ These differences could be the result of the higher dosages used in the second study. Thus, it seems that CCK-8, in the cat at least, may have differential effects dependent on the concentration.

In an in vitro rat gastroduodenal preparation, CCK-8 has been found to stimulate phasic pyloric contractions via direct action on smooth muscle, and tonic contractions via a noncholinergic neural mechanism. ${ }^{17}$ Isenberg and Csendes reported that in dogs there is a dosedependent increase in basal pyloric pressures after intravenous CCK-8 infusion, ' but the manometric technique used in this study may not be reliable, and this finding should be interpreted with caution. Yamagishi and Debas reported, also in dogs, that the retardant action of low dose CCK-8 infusion on gastric emptying was abolished after both pyloroplasty and antrectomy, ${ }^{18}$ suggesting that the pylorus was the primary mechanism for this effect. Truncal vagotomy abolished the inhibitory effect of all doses of CCK-8, and acceleration of gastric emptying was only seen after subsequent destruction of pyloric mechanisms. ${ }^{18}$ This suggested that CCK-8 slowed gastric emptying via a vagally dependent mechanism acting on the pylorus and the proximal stomach. ${ }^{19}$ However, truncal vagotomy is a relatively non-selective procedure with multiple effects on gastric and duodenal motility. As these may also significantly modify gastric emptying, this interpretation may not be justified.

Recently Allescher et al have used both intraluminal manometry and implanted strain gauges to evaluate patterns of pyloric and antral motility in dogs after close intra-arterial injection of CCK-8. ${ }^{9}$ Although the tonic and phasic responses were not reported separately, their results also indicated that these responses have both neural and tetrodotoxin-insensitive (that is, direct) components depending on the dose of CCK-8. Lopez et al ${ }^{20}$ reported in the dog that CCK8 (500 ng $\mathrm{kg}^{-1} \mathrm{~h}^{-1}$ iv) decreased postprandial pyloric electrical spike activity, but did not determine whether this represented a reduction in electrical activity that was isolated in the pylorus. Their data are therefore not comparable with those from our study.

Our studies showed no effect of atropine on the phasic pyloric motor response to $10 \mathrm{ng} / \mathrm{kg}$ of CCK-8. This is at variance with the findings of the studies of Allescher et al, which showed attenuation with atropine at lower CCK-8 dosages. ${ }^{9}$ This difference may reflect interspecies variation, or possibly the relatively high CCK- 8 dosage used in our study. In humans, the phasic pyloric motor response to intraduodenal lipid and dextrose is dependent on muscarinic mechanisms ${ }^{21} 22$; our observation that the pyloric motor response to $10 \mathrm{ng} / \mathrm{kg} \mathrm{CCK-8}$ is not modified by atropine administration suggests that CCK is not the major mediator of small 
intestinal feedback to the pylorus. However, this should be interpreted with caution, as the relatively high doses of CCK-8 in our study may have caused direct stimulation of the pyloric smooth muscle and overide any muscarinic dependency as described in the dog.

Although recent studies have reported contradictory effects on gastric emptying after administration of CCK antagonists, ${ }^{3+}$ cholecystokinin is thought to be important in the regulation of postprandial gastric motility. The antropyloric contractions seen after the IPPW response in some of the studies are similar to the pattern of contractions reported by Houghton et al after a mixed meal. ${ }^{13} \mathrm{It}$ is of interest that after exogenous administration of CCK-8 we recorded effects on gastroduodenal motility that may both retard and accelerate gastric emptying, although we were not in a position to judge whether either of these occurred at physiological concentrations of CCK. These antropyloric waves were not seen after atropine, consistent with the findings of Kuwahara et al, who reported that the effects of CCK on the gastric antrum in dogs were completely abolished by atropine. ${ }^{23} \mathrm{~A}$ differential effect of CCK-8 on contraction of human gastric smooth muscle strips has been reported in vitro, depending both on the dose of CCK- 8 and the section of the stomach from which the muscle strip originated..$^{24}$

The primary aim of this study was to determine whether CCK-8, a putative mediator of pyloric motility, had any effect on pyloric contractions in healthy humans. The doses of CCK-8 used in this study were larger than those reported to slow gastric emptying and may well be pharmacological. In addition, CCK is distributed widely in the enteric nervous system and it is impossible to determine whether blood concentrations of CCK accurately reflect tissue levels. Preparations of CCK may also contain impurities and assays for CCK may be subject to variable binding. The CCK- 8 concentration under 'physiological' conditions is unclear. The physiological activity of hormone sub-fractions such as CCK-8 is also uncertain, and thus infusions of lower concentrations of CCK-8 will not clarify whether the effect on the pylorus is physiological. Studies with specific antagonists ${ }^{3+}$ will be required to dissect the role of CCK in postprandial and nutrient stimulated gastric motor function.

In conclusion, intravenous cholecystokinin infusion produces a pattern of antral, pyloric, and duodenal motility that has previously been described with other stimuli which also retard gastric emptying. The pyloric motor response to CCK-8 is dose-dependent, and not mediated by muscarinic mechanisms. It should be recognised that proximal gastric and small intestinal motility may also be important in the regulation of gastric emptying, ${ }^{25} 26$ and interpretation of our findings should be limited to the fasted state. Further measurements are therefore necessary to determine whether the slowing of postprandial gastric emptying by CCK- 8 is mediated via these effects on antropyloroduodenal motility.

The authors thank Sue Graham for technical assistance during the study, Jill Hanley and Jo Fuller for assistance in preparing the manuscript, and Virginia Sharley of the Pharmacy Department at the Roval Adelaide Hospital for preparing and coding the CCK-8 injections.

The study was supported by a National Health and Medical Research Council project grant. Dr Fraser was supported by a National Health and Medical Research Council Postgraduate Research Scholarship. Part of this study was presented in abstract form at the American Gastroenterology Association meeting in May 1990.

1 Liddle RA, Morita ET, Conrad CK, Williams JA. Regulation of gastric emptying in humans by cholecystokinin. 7 Clin Invest 1986; 77: 992-6.

2 Kleibeuker JH, Beekhuis H, Jansen JBMJ, Piers DA, Lamers CBHW. Cholecystokinin is a physiologic hormonal mediator of fat-induced inhibition of gastric emptying. Eur f Clin Invest 1988; 18: 173-7.

3 Meyer BM, Beglinger C, Jansen JBMJ, Rovati LC, Werth BA Hilderbrand $\mathrm{P}$, et al. Role of cholecystokinin in regulation of gastrointestinal motor functions. Lancet 1989; i: 12-5.

4 Liddle R, Gertz B, Kanayama S, Beccaria L, Coker L, Turnbull T, et al. Effects of a novel cholecystokinin (CCK antagonist, $\mathrm{MK}-329$, on gallbladder contraction and gastric emptying in humans. $\mathcal{F}$ Clin Invest 1989; 84: 1220-5.

5 Heddle R, Collins PJ, Dent J, Horowitz M, Read NW, Chatterton $\mathrm{B}$, et al. Motor mechanisms associated with slowing of the gastric emptying of a solid meal by an intraduodenal lipid infusion. $\mathcal{F}$ Gastroenterol Hepatol 1989; 4 437-47.

6 Tougas G, Anvari M, Richards D, Dent J, Somers S, Stevenson GW. Relationship of pyloric motility to transpyloric flow in healthy subjects. Gut 1992; 33: pyloric

7 Isenberg JI, Csendes A. Effect of octapeptide of cholecystokinin on canine pyloric pressure. Am $\mathcal{F}$ Physiol 1972; 222 428-31.

8 Valenzuela J. Effect of intestinal hormones and peptides on intragastric pressure in dogs. Gastroenterology 1976; 71: 766-9.

9 Allescher HD, Daniel E, Fox J, Kostolanska F, Rovati L, Effect of the novel cholecystokinin receptor antagonist CR-1392 on cholecystokinin induced antroduodenal and pyloric motor activity in vivo. $\mathcal{F}$ Pharmacol Exp Ther 1989; 251: $1134-41$.

10 Phaosawasdi K, Fisher RF. Hormonal effects on the pylorus. Am f Physiol 1982; 243: G330-5.

11 Heddle R, Dent J, Read NW, Houghton LA, Toouli J, Horowitz $M$, et al. Antropyloroduodenal motor responses to intraduodenal lipid infusion in healthy volunteers. Am $\mathcal{f}$ Physiol 1988; 254: G671-9.

12 Heddle $R$, Fone D, Dent $J$, Horowitz $M$. Stimulation of pyloric motility by intraduodenal dextrose in normal subjects. Gut 1988; 29: 1349-57.

13 Houghton L, Read N, Heddle R, Horowitz M, Collins P, Chatterton B, et al. Relationship of the motor activity of the antrum, pylorus, and duodenum to gastric emptying of solid-liquid mixed meal. Gastroenterology 1988; 94: 1285-91.

14 Munk JF, Gannaway RN, Hoare M, Johnson AG. Direct measurement of pyloric diameter and tone in man and their response to cholecystokinin. In: Duthie HL, ed. Gastrointestinal motility in health and disease. Lancaster, UK: MTP Press, 1978: 349-59.

15 Behar J, Biancani P, Zabinski MP. Characterisation of feline gastroduodenal junction by neural and hormonal stimugastroduodenal junction by neural and
lation. Am 7 Physiol 1979; 236: E45-51.

16 Reynolds JC, Ouyang A, Cohen S. Opiate nerves mediate feline pyloric response to intraduodenal aminoacids. $A m \mathcal{F}$ Physiol 1985; 248: G307-12.

17 Scheurer U, Varga L, Drack E, Burki HR, Halter F. Mechanism of action of cholecystokinin octapeptideinduced motility of rat antrum, pylorus and duodenum. $\mathrm{Am}$ f Physiol 1983; 244: G261-5.

18 Yamagishi T, Debas HT. Cholecystokinin inhibits gastric emptying by acting on both proximal stomach and pylorus. Am F Physiol 1978; 234: E375-8.

19 Allescher HD. Enteric nerves and hormones. In: Van Nueten JM, Schuurkes JA J, Akkermans LMA, ed. Gastro-pyloroduodenal coordination. Petersfield: Wrightson Biomedical duodenal coordination. Pe

20 Lopez Y, Floramonti J, Bueno I. Central and peripheral control of postprandial pyloric motility by endogenous opiates and cholecystokinin in dogs. Gastroenterology 1991; 101: 1249-53.

21 Fraser R, Fone D, Horowitz M, Dent J, Graham S, Heddle R. Pyloric motor reponse to intraduodenal lipid is sustained and atropine sensitive. Gastroenterologv 1989; 96: A 157.

22 Fone D, Horowitz M, Dent J, Read NW, Heddle R. Pyloric motor response to intraduodenal dextrose involves muscarinic mechanisms. Gastroenterology 1989; 97: 83-90.

23 Kuwahara A, Ozawa K, Yanaihara N. Effects of cholecystokinin-octapeptide on gastric motility of anaesthetised dogs. Am F Physiol 1986; 251: G678-81.

24 Ludtke F, Golenhofen K, Kohne C. Direct effects of cholecystokinin on human gastric motility. Digestion 1988; 39: $210-8$

25 Aspiroz F, Malagelada JR. Intestinal control of gastric tone. Am F Phusiol 1985; 249: G934 43 .

26 Horowitz M, Dent J. Disordered gastric emptying: mechanical basis, assessment and treatment. Baillieres Clin (jastroenterol 1991; 5: 371-407. 